\title{
ARQUIVOS PÚBLICOS BRASILEIROS: ANÁLISE DA EVOLUÇÃO DA TRANSFERÊNCIA DA INFORMAÇÃO ARQUIVÍSTICA NA INTERNET
}

\author{
BRAZILIAN PUBLIC ARCHIVES: THE TRANSFERENCE OF INFORMATION ON THE \\ INTERNET
}

Anna Carla Almeida Mariz
Doutora em Ciência da Informação, UFRJ-IBICT, mestre em Memória Social e Documento e
bacharel em Arquivologia pela UNIRIO.
Professora adjunta da UNIRIO desde 1991.
Diretora da Escola de Arquivologia da UNIRIO desde 2006.
Universidade Federal do Estado do Rio de Janeiro - UNIRIO
annacarla@unirio.br

\section{Resumo}

Estudo da evolução da inserção das Instituições Arquivísticas Públicas Brasileiras na internet e dos processos de transferência da informação arquivística nessa rede. A primeira etapa da pesquisa, em 2004, teve como marco empírico o universo existente dos sites de Instituições Arquivísticas Públicas Brasileiras. Na segunda fase, em 2009, foi atualizado o universo para análise e investigados os sites, tendo como parâmetros os mesmos critérios da etapa anterior: serviços que disponibilizam, nível de relacionamento com o usuário, que tipo de consulta pode ser feita ao acervo e elementos relativos aos conteúdos, desenho e estrutura dos sites. A importância deste estudo comparativo está em verificar as mudanças que ocorreram neste intervalo, se houve crescimento, avanços e quais foram. O site de uma instituição arquivística oferece serviços já existentes no local, total ou parcialmente, além de sugerir novas possibilidades às instituições arquivísticas. Este espaço informacional exige ações voltadas para atender às demandas produzidas pelos usuários da rede. A inserção dos acervos arquivísticos na Internet implica em novos desafios na gestão desta informação.

Palavras-chave: 1. Arquivos públicos - Brasil. 2. Internet (Redes de computação). 3. Sites da Web - Pesquisa. 4. Sistemas de recuperação da informação - Arquivos.

\section{INTRODUÇÃ̃}

Pode-se verificar que a inserção das instituições arquivísticas na internet vem crescendo, e pesquisas realizadas em diferentes épocas comprovam isso.

A presença de uma instituição arquivística na internet e os serviços que ela oferece pela rede refletem a sua atuação como instituição arquivística anterior e independente da internet. Se ela não tem boa estrutura para atender de maneira presencial, tais como acervo devidamente tratado,

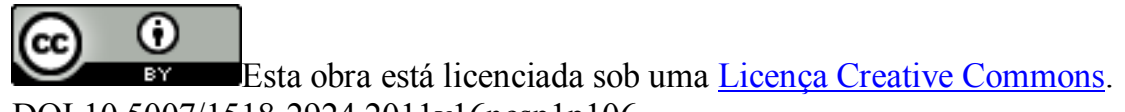

DOI 10.5007/1518-2924.2011v16nesp1p106

Enc. Bibli: R. Eletr. Bibliotecon. Ci. Inf., Florianópolis, n. esp., 1º sem. 2011. ISSNe 1518-2924. 
pessoal qualificado para tratamento do acervo e atendimento ao público, instrumentos de pesquisa, não vai poder oferecer condições diferentes no plano virtual. A transferência da informação que a instituição arquivística proporciona pela internet não pode ser tão distinta da que ela proporciona no local onde está instalada.

A base da transferência da informação na instituição arquivística está principalmente em como o acervo está organizado, nos recursos humanos disponíveis, nos instrumentos de pesquisa que existem, entre outros. E essa estrutura vai ser necessária tanto para o atendimento presencial quanto para o atendimento à distância. A instituição não tem condições de atender à distância, se não tiver condições de atender no local, na sala de consulta.

Muitas pesquisas ${ }^{1}$ e estudos sobre as instituições arquivísticas públicas brasileiras foram empreendidos e detectaram que essas instituições passam por muitas dificuldades em termos de recursos: humanos, físicos, materiais, tecnológicos, equipamentos, espaço, entre outros. Isso impede que os acervos estejam disponíveis e acessíveis. Em alguns casos, existem dificuldades até no que diz respeito à formação dos acervos: há administrações públicas que não recolhem da maneira que deveriam e algumas instituições ficam com acervos incompletos ou até mesmo sem valor permanente.

As instituições que têm problemas desta natureza não têm como oferecer um trabalho de qualidade pela internet. O bom trabalho depende em primeiro lugar do acervo, depende da existência, da boa organização e da boa recuperação da informação, do acesso legal, físico e intelectual. Da mesma forma, não é suficiente ter uma boa estrutura de tecnologia da informação se a instituição não estiver bem estruturada nos outros aspectos.

Assim, a transferência da informação pela internet depende da transferência da informação que já é feita na instituição no local onde está instalada, de maneira presencial.

\footnotetext{
1 Várias pesquisas foram consultadas, porém quatro foram usadas com maior destaque. Em 1996 foram desenvolvidas duas pesquisas muito significativas sobre as instituições arquivísticas públicas no Brasil, pela abrangência, profundidade e seriedade. Uma teve como objeto os arquivos municipais, desenvolvida por Maria Odila Fonseca e a outra, os arquivos estaduais, desenvolvida por Maria Regina P. Armond Côrtes. Uma outra investigação sobre arquivos municipais foi realizada em 2002, seguindo a mesma linha das pesquisas citadas, tendo como universo o estado de Santa Catarina (Ohira e Martinez). E ainda a Fundação Histórica Tavera (Espanha) desenvolveu uma pesquisa sobre os arquivos brasileiros a pedido do Banco Mundial, para a Mesa-Redonda Nacional de Arquivos realizada no Rio de Janeiro em 1999.
} 
As instituições arquivísticas públicas brasileiras expressam, ao longo da sua trajetória e atual perfil, a forma como se inserem no Estado. Segundo Jardim, se encontram em um lócus periférico. (1999b).

As pesquisas mencionadas têm por objeto arquivos municipais e/ou estaduais e pretendem chegar a um diagnóstico da situação dessas instituições arquivísticas no Brasil. Ainda que as primeiras sejam de 1996 e a mais recente de 2002, os resultados não apresentam grandes divergências. Demonstram que as instituições arquivísticas municipais e estaduais brasileiras não têm o acervo tratado em sua totalidade, no que diz respeito ao arranjo e, em alguns casos, à identificação. É precária também a situação no que se refere à existência de Instrumentos de Pesquisa. As dificuldades na área de tratamento técnico são consequências da falta de infraestrutura de um modo geral: material, recursos, equipamentos, espaço e principalmente da carência de recursos humanos, em especial de profissionais com capacitação arquivística. Foi apontada também a falta de recolhimento periódico, de programa de gestão de documentos e de tabela de temporalidade. Em muitos casos, existem acervos sem possibilidade de acesso físico, por estarem acumulados em depósitos que não oferecem condições para tal. Em outros casos, o simples fato de o acervo não estar identificado ou arranjado e a inexistência de instrumentos de pesquisa também impossibilitam o acesso. Tais problemas dificultam e, em alguns casos, impedem o acesso à informação arquivística nas instituições, independentes e anteriores ao advento da internet.

Apesar de todos os problemas enfrentados pelas instituições arquivísticas públicas brasileiras, a presença dessas instituições na internet vem aumentando.

A internet, inicialmente pensada para a pesquisa acadêmica, tornou-se rapidamente um meio de comunicação de massa e, como espaço informacional, oferece inúmeras novas possibilidades aos arquivos.

As instituições arquivísticas estão se deparando com um desafio, o da época das redes eletrônicas, que virá a se somar às suas atividades anteriores. Frente às novas tecnologias da informação que possibilitam as redes eletrônicas, é de fundamental importância repensar todas as ações teórico-práticas que condicionariam os arquivos. Faz-se imperativo questionar suas premissas de gestão e difusão de documentos mediante a disponibilização de seu acervo na Internet. 
A disponibilização de acervos arquivísticos na internet apresenta muitas vantagens - facilitar o acesso, atingir um público maior, ampliar o atendimento aos pesquisadores, permitir pesquisas, aumentar a divulgação, dentre outras; cabe realmente utilizar-se delas.

O estabelecimento de um site trará significativa ampliação da atuação das Instituições Arquivísticas.

\begin{abstract}
"O website de uma instituição arquivística deve ser visto como um instrumento de prestação de serviços - dinâmico e atualizável - e não simplesmente como a reprodução de um folder institucional. Trata-se, na verdade, de um espaço virtual de comunicação com os diferentes tipos de usuários da instituição a ser gerenciado como parte da política de informação da instituição. Dado o potencial e as características da Internet, este espaço, além de redefinir as formas de relacionamento com os usuários tradicionais, poderá atrair outros que, por várias razões, difícil ou raramente procurariam o Arquivo como realidade física" (CONARQ, 2000, 4).
\end{abstract}

Essa maior visibilidade das instituições arquivísticas na internet vem sendo verificada por meio de pesquisas realizadas em diferentes épocas, com cada vez mais progressos nos resultados, ainda que não tão satisfatórios quanto os de outras instituições e/ou serviços públicos.

Foram investigados os sites de Instituições Arquivísticas públicas brasileiras na internet. A primeira busca se deu no ano de 2004 para identificar as instituições presentes na rede. A coleta de dados consistiu no preenchimento de um formulário para cada site com os critérios a serem analisados. Ao entrar no endereço eletrônico para proceder o preenchimento do referido formulário, percebeu-se, através das características, se se tratava ou não de um site ${ }^{2}$. Assim, em 2004, dos 29 endereços de instituições arquivísticas disponíveis, 20 (vinte) são sites, 1 (um) estava em atualização, portanto não dispunha de todas as seções, e 8 (oito) são páginas dentro de outros sites (de Secretarias de Cultura ou de Prefeitura, por exemplo). Em 2004, a análise foi feita nos vinte sites existentes: 1 (um) do Arquivo Nacional, 10 (dez) estaduais e 9 (nove) municipais. As nove páginas também foram observadas, porém sob outro referencial, uma vez que o universo definido para a pesquisa compreende os sites.

\footnotetext{
2 Existe uma diversidade de abordagens em relação à terminologia e no que diz respeito a sites e páginas. Para efeito desta pesquisa, são considerados:

"Site ("sítio"): conjunto de documentos de uma localidade ou instituição, formatados em HTML, colocados à disposição dos usuários da Internet.

Página web ou simplesmente página: qualquer documento formatado em HTML de um site ou de um servidor www”. (Unesp: 2000).
}

Enc. Bibli: R. Eletr. Bibliotecon. Ci. Inf., Florianópolis, n. esp., 1º sem. 2011. ISSNe 1518-2924. 
Uma nova fase da pesquisa foi desenvolvida em 2009, visando obter novos resultados, averiguar como está a transferência da informação arquivística na internet depois de cinco anos, além de poder comparar com os resultados anteriores, principalmente os de 2004. Para isto, novamente foi feito o levantamento de quantas e quais são as Instituições Arquivísticas Públicas Brasileiras que estão de alguma forma presentes na internet e, em seguida, foi aplicado a todas elas o mesmo questionário utilizado em 2004, para possibilitar a comparação dos resultados.

Em 2009, foram levantados 54 (cinquenta e quatro) URLs. Durante a análise de cada uma das URLs, verificou-se que alguns deles não se configuram em sites ou páginas. Alguns apenas mencionam as Instituições, mas não são sites institucionais ou sobre a instituição. Assim, em 2009 o total foi fixado em 47 instituições na internet, e a análise foi feita nos 26 sites existentes: 1 (um) do Arquivo Nacional, 9 (nove) estaduais e 16 (dezesseis) municipais. Da mesma forma que foi feito em 2004, as dezenove páginas e os dois blogs ${ }^{3}$ também foram analisados, mas sob outro referencial, já que o universo definido para a pesquisa compreende os sites.

A análise dos sites identificados, nas duas ocasiões, tem como parâmetros os seguintes critérios: serviços que disponibilizam, qual o nível de relacionamento com o usuário, que tipo de consulta pode ser feita ao acervo e elementos relativos aos conteúdos, desenho e estrutura dos sites.

Os parâmetros definidos no documento "Diretrizes gerais para a construção de websites de instituições arquivísticas" do Conselho Nacional de Arquivos (CONARQ) de dezembro de 2000 são estudados e considerados como instrumento de análise dos sites que integram o campo empírico da pesquisa.

Os sites das instituições arquivísticas estaduais em 2004 são:

- Arquivo Público do Estado do Rio - Arquivo Público do Paraná Janeiro

- Arquivo do Estado de São Paulo

- Arquivo Público do Estado de Santa Catarina

\footnotetext{
${ }^{3}$ Um blog (contração do termo "Web log") é um site cuja estrutura permite a atualização rápida a partir de acréscimos dos chamados artigos, ou "posts". Estes são, em geral, organizados de forma cronológica inversa, tendo como foco a temática proposta do blog, podendo ser escritos por um número variável de pessoas, de acordo com a política do blog. Muitos blogs fornecem comentários ou notícias sobre um assunto em particular; outros funcionam mais como diários online. Um blog típico combina texto, imagens e links para outros blogs, páginas da web e mídias relacionadas a seu tema. A capacidade de leitores deixarem comentários de forma a interagir com o autor e outros leitores é uma parte importante de muitos blogs.

Enc. Bibli: R. Eletr. Bibliotecon. Ci. Inf., Florianópolis, n. esp., $1^{\text {o }}$ sem. 2011. ISSNe 1518-2924. 
- Arquivo Público do Estado do Espírito - Arquivo Público do Estado do Pará Santo

- Arquivo Público Mineiro

- Arquivo Público de Mato Grosso
- Arquivo Público do Rio Grande do Norte

- Arquivo Público Estadual Jordão Emerenciano (PE)

Os sites das instituições arquivísticas estaduais em 2009 são:

- Arquivo Público do Estado do Rio - Arquivo Público do Paraná Janeiro

- Arquivo do Estado de São Paulo

- Arquivo Público do Estado do Espírito Santo

- Arquivo Público Mineiro

- Arquivo Público do Distrito Federal - DF

Os sites de instituições arquivísticas municipais em 2004 são:

- Arquivo Geral da Cidade do Rio de Janeiro - RJ

- Arquivo Público do Município de Belo Horizonte - MG

- Arquivo Histórico de Juiz de Fora - MG

- Arquivo Histórico de Porto Alegre Moysés Vellinho - RS

- Arquivo Histórico do Município de Salvador / FGM (Fundação Gregório de Mattos) - BA

- Arquivo Público de Uberaba - MG

- Arquivo Histórico do Município de São Paulo - SP

- Arquivo Público Municipal (e Arquivo Geral) de Santos - Arquivo Memória de Santos - SP

- Arquivo Público Municipal de Indaiatuba - SP

Os sites das instituições arquivísticas municipais em 2009 são:

- Arquivo Geral da Cidade do Rio de Janeiro - RJ

- Arquivo Público do Município de Belo Horizonte - MG

Enc. Bibli: R. Eletr. Bibliotecon. Ci. Inf., Florianópolis, n. esp., $1^{\circ}$ sem. 2011. ISSNe 1518-2924. 
- Arquivo Histórico de Juiz de Fora - MG

- Arquivo Histórico de Porto Alegre Moysés Vellinho - RS

- Arquivo Histórico do Município de Salvador / FGM (Fundação Gregório de Mattos) - BA

- Arquivo Histórico Municipal de Florianópolis - Professor Oswaldo Rodrigues Cabral - SC

- Arquivo Histórico da Fundação Promemória de São Carlos - SC

- Arquivo Público de Uberaba - MG

- Arquivo Histórico do Município de São Paulo - SP

- Arquivo Público Municipal (e Arquivo Geral) de Santos - Arquivo Memória de Santos - SP

- Arquivo Histórico de Joinville - SC

- Arquivo Histórico José Ferreira da Silva - Blumenau - SC

- Arquivo Histórico Municipal João Spadari Adami - Caxias do Sul - RS

- Arquivo Público e Histórico de Ribeirão Preto - SP

- Arquivo Municipal do Jaraguá do Sul -

- Arquivo Público de Campos dos Goytacazes - RJ

$\mathrm{Na}$ análise de $\mathbf{2 0 0 4}$ as páginas eram os seguintes:

- Arquivo Público Estadual de Sergipe - Arquivo Histórico Municipal de Americana

- Arquivo Público do Estado da Bahia - Arquivo Público do Estado do Rio Grande do Sul

- Arquivo Público do Estado do Ceará - Arquivo Histórico Municipal Professor Oswaldo

- Arquivo Público Municipal de Rodrigues Cabral (Florianópolis)

Paracatu

- Arquivo Histórico Municipal de Tietê - Arquivo Histórico da Fundação Promemória de São Carlos

Na análise de 2009 as páginas são os seguintes: ARQUIVOS ESTADUAIS

- Arquivo Público do Estado da Bahia

- Arquivo Público do Estado do Ceará

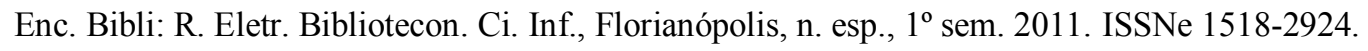


- Arquivo Público de Mato Grosso

- Arquivo Histórico do Rio Grande do Sul

- Arquivo Público Estadual Jordão Emerenciano - Pernambuco

- Arquivo Público Estadual de Sergipe

ARQUIVOS MUNICIPAIS

- Arquivo Histórico de Balneário de Camboriú

- Arquivo Histórico de Campo Grande - MS

- Arquivo Histórico de Canoinhas - SC

- Arquivo Histórico Municipal - João Leopoldo Lied - Gramado - RS

- Arquivo Histórico Municipal "Historiador Isaac Grinberg" - Mogi das Cruzes - SP

- Arquivo Histórico Municipal Juarez Miguel Illa Font - Erechim - RS

- Arquivo Municipal de Rio de Contas - BA

- Arquivo Municipal de Rondópolis - MT

- Arquivo Público Municipal de São José dos Campos - SP (Fundação Cultural Cassiano Ricardo)

- Arquivo Municipal de Campinas - SP

- Arquivo Publico e Histórico de Jacareí - SP

- Arquivo Público Municipal de Indaiatuba - SP

- Arquivo Público Municipal de Uberlândia - MG

Os blogs, em 2009, são: Arquivo Público da cidade de Paracatu - MG e Arquivo Histórico Municipal de Resende - RJ.

\section{ANÁLISE DOS SITES E PÁGINAS - EVOLUÇÃo}

O crescimento pode ser analisado segundo vários aspectos: pela esfera de competência, pela forma como se apresenta na internet, pela região do Brasil, e, ainda, pela comparação das várias pesquisas, ou seja, a evolução desse crescimento.

Enc. Bibli: R. Eletr. Bibliotecon. Ci. Inf., Florianópolis, n. esp., $1^{\text {o }}$ sem. 2011. ISSNe 1518-2924. 
O Arquivo Nacional é a única instituição no patamar federal e seu site está presente na internet desde a primeira verificação, em 1996, portanto nessa esfera não poderia haver crescimento.

Em relação às Instituições Estaduais, o número de sites diminui de 10, em 2004, para 9, em 2009, ou seja, menos 10\%, e o número de páginas aumenta de 4, em 2004, para 6, em 2009, um aumento de 50\%. Somando os sites e as páginas, temos 14 em 2004 e 15 em 2009, o que representa um aumento discreto de cerca de $8 \%$.

No que diz respeito às Instituições Municipais, temos os seguintes índices de crescimento: sobre os sites, em 1999, são apenas 2, em 2004 já são 9, o que representa um aumento de 350\%, e em 2009 são 16, o que significa um aumento de 78\% em relação à 2004 e de $700 \%$ em relação à 1999. Sobre as páginas, em 2004, temos 5 e, em 2009, são 13, o que representa um aumento de $160 \%$.

Se somarmos os sites e as páginas das instituições arquivísticas municipais, temos 14 em 2004 e 26 em 2009, um aumento de 86\%. E se forem incluídos os blogs, o número passa a ser 28 em 2009, e o aumento de $100 \%$.

As instituições municipais são as que apresentam um maior índice de crescimento, já que o nível federal não pode crescer e a chance de aumento dos sites e páginas dos Arquivos Estaduais é menor, pois temos um número máximo de Arquivos Estaduais no país, 27.

São 27 estados, incluindo o Distrito Federal e apenas o estado do Tocantins ainda não têm Instituição Arquivística. Os 26 arquivos públicos estaduais apresentam graus diferentes de desenvolvimento técnico. Ainda assim, 15 (56\%) instituições estaduais na internet, apesar de serem maioria, ainda são poucas e o crescimento apontado nas diversas verificações para essa esfera é mínimo (8\%).

Já os arquivos municipais têm um aumento muito significativo. Existem mais instituições arquivísticas municipais e por esse crescimento podemos perceber que muitas estão numa situação até melhor do que algumas estaduais.

Como exemplo, temos a pesquisa de Ohira e Martinez sobre o Estado de Santa Catarina, onde as autoras mencionam que dos 293 municípios, somente 25 cidades (8,53\%) possuem arquivos públicos institucionalizados (2002). 
Em relação às instituições arquivísticas municipais, não há como saber ao certo quantas existem no país, para determinar a porcentagem que representa do total. A grande maioria dos 5565 municípios brasileiros não tem arquivos institucionalizados.

Dentre as 9 instituições municipais com sites verificadas, em 2004, 5 são instituições de capitais dos estados (55\%): Rio de Janeiro, Minas Gerais, São Paulo, Rio Grande do Sul e Bahia. O site da capital do estado de Santa Catarina, por não estar funcionando em sua totalidade, foi considerado e analisado como página.

Em 2009, dentre as 16 instituições municipais com sites, são 6 os de capitais de estados (38\%), as mesmas de 2004, incluindo a de Florianópolis (SC), já em total funcionamento. Entre as 19 páginas, só uma é de capital, do estado de Mato Grosso do Sul. As instituições municipais de capitais dos estados com sites permanecem praticamente sem alterações, porém a porcentagem dessas instituições diminuiu de uma consulta para a outra, uma vez que o aumento das instituições de municípios que não são capitais foi maior.

Os sites aumentaram de 3 em 1996 para 13 em 1999, ou seja, 330\%. De 13 para 20 em 2004, o que representa 54\% e de 20 para 26 em 2009, o que significa 30\%. Houve crescimento em todas as verificações, mas esse crescimento foi diminuindo em cada consulta. O que representa um aumento muito alto no início, nas últimas comparações já é menor.

As páginas aumentaram de 9 em 2004 para 19 em 2009, ou seja 110\%. O índice de aumento das páginas é bem maior que o dos sites. Os sites exigem um esforço maior para a elaboração, mais conteúdo, mais recursos, mais espaço de armazenamento, entre outros. As páginas são mais simples: menores, ligadas a sites de outros órgãos, como, por exemplo, da prefeitura ou do governo do Estado, consequentemente mais fáceis de serem criadas e mantidas.

O crescimento analisado, levando em consideração a localização geográfica das instituições, chama a atenção para a grande concentração dessas instituições na Região Sudeste.

Tanto em 2004 quanto em 2009, todos os estados da Região Sudeste têm sites das suas instituições estaduais. A região Sul, em 2004, apresenta duas instituições arquivísticas com sites e, em 2009, já são três, ou seja, a totalidade dos estados.

Nas outras regiões, a situação é bem diferente. No nordeste, que tem nove estados, apenas 2 (duas) instituições arquivísticas estaduais têm sites, em 2004, (22\% dos estados) e não tem Enc. Bibli: R. Eletr. Bibliotecon. Ci. Inf., Florianópolis, n. esp., 1º sem. 2011. ISSNe 1518-2924. 
nenhum em 2009. Na região centro-oeste, com 3 estados e o Distrito Federal, tem apenas um site, tanto em 2004 quanto em 2009, o que representa 25\% dos estados. E na região norte, que tem 6 estados, também tem apenas um site nas duas coletas de dados, em 2004 e 2009, o que significa 17\% dos estados. Se incluirmos as páginas, o nordeste tem 3 em 2004, total de 5 (55\% dos estados) e 4 em 2009, total de 4 (44\% dos estados). E uma página na região centro-oeste em 2009 , total de 2 , ou $50 \%$ das instituições estaduais.

Em 2004, 40\% das instituições estaduais presentes na internet estão na região sudeste e, em 2009, o mesmo número de instituições representa $44 \%$ do total. E a região sul, em 2004 , tem $20 \%$ das instituições e, em 2009, já aparece com 34\%. As duas regiões somadas representam 60\% em 2004 e $78 \%$ em 2009.

Fica muito clara, assim como nas instituições estaduais, a grande predominância das regiões sudeste e sul. A soma das duas regiões chega a 89\% em 2004 e a 94\% em 2009. Em ambos os casos aparece apenas um site de instituição municipal fora destas duas regiões, no nordeste. Deve-se registrar o aumento da participação da região sul nesse total, em 2004 significa 11\% e em 2009 representa 44\%, aumentando de 1 site para 7. Especialmente, nesse resultado da região sul, destaca-se o estado de Santa Catarina, que, em 2004, não apresenta nenhum site de instituição municipal e, em 2009, aparece com 5, além de ser o estado com mais sites de instituições arquivísticas municipais em 2009, registra uma evolução sem igual também entre os outros estados. Santa Catarina representa $31 \%$ dos sites de instituições arquivísticas municipais no Brasil.

Se somarmos todas as formas de inserção na internet (sites, páginas e blogs), ainda assim predomina a região sudeste, que, na consulta de 2004, aparece com 15 (52\%) e na de 2009 com $20(43 \%)$.

A região sul apresenta um aumento expressivo de 5 (17,2\%) em 2004 para 15 (32\%) em 2009. Desses 15, 7 (sete) são do estado de Santa Catarina - que em 2004 tem apenas 1 - e 6 são do Rio Grande do Sul - que em 2004 tem 2. O nordeste manteve o número de sites/páginas em 6, tanto em 2004 quanto em 2009, mas isso representa uma diminuição na porcentagem, de 20\% para $13 \%$. O norte também manteve em 1, o que significa queda na porcentagem de 3,6\% em 2004 para $2 \%$ em 2009. A região centro oeste aumenta de 1 para 4 sites/páginas $(3,6 \%$ para $8 \%)$. 
Comparando também com pesquisas anteriores feitas por Jardim em 1996 e 1999 (1999a). A de 1996 tem um resultado de 3 sites, a de 1999 tem um resultado de 13 sites, o que representa um aumento de 330\% em três anos. A de 2004, onde são encontrados um total de 29 sites/páginas, representa um aumento de $130 \%$ em relação a 1999 num intervalo de 5 anos e um aumento de $860 \%$ em relação a 1996 em um intervalo de 8 anos.

A consulta de 2009 apresenta um resultado de 47 sites/páginas/blogs, o que representa um aumento de $63 \%$ em relação a 2004 com um intervalo de 5 anos, um aumento de $260 \%$ em relação a 1999 com um intervalo de 10 anos e um aumento de 1480\% em relação a 1996 em um intervalo de 13 anos.

Podemos ver que há crescimento da inclusão das instituições arquivísticas públicas brasileiras na internet na quase totalidade dos aspectos, seja pela esfera de competência da instituição, pela maneira que se apresenta na internet, entre outros. Os maiores índices de crescimento foram detectados nos arquivos municipais e na Região Sul, especialmente no estado de Santa Catarina.

\section{ANÁLISE DOS SITES E PÁGINAS - CONTEÚDO E ESTRUTURA CONTEÚDO - ASPECTOS GERAIS}

Para que o visitante faça um bom uso do site e consequentemente da instituição arquivística, é necessário que ele seja informado sobre o que é o arquivo e o tipo de informação que ele pode obter na instituição. O site deve conter esse tipo de esclarecimento, visando contextualizar a documentação e as condições de surgimento dos acervos. A página de abertura é o ponto de partida aos vários conteúdos e páginas dos sites. A partir dela, é determinado o caminho a ser seguido por cada usuário.

Em relação às informações sobre a Instituição, todos os índices aumentaram de forma expressiva. Essas informações sobre a instituição são mais frequentes, mas, ainda assim, em 2004, não eram todos que apresentavam.

As informações sobre o histórico da instituição estão presentes na quase totalidade dos sites na primeira etapa e em todos na segunda etapa. Muitos deles não têm outras informações importantes, tais como em relação aos instrumentos de pesquisa, mas incluem o histórico. Esse fato pode ter relação com o forte caráter histórico das instituições.

Enc. Bibli: R. Eletr. Bibliotecon. Ci. Inf., Florianópolis, n. esp., $1^{\circ}$ sem. 2011. ISSNe 1518-2924. 
As indicações sobre endereço, telefone (às vezes as formas de acesso), na etapa de 2004, estavam em 19 (dezenove) sites, 95\%. Essas indicações são importantes na medida em que a maior parte das pesquisas ainda é feita de forma presencial, na sala de consulta dos arquivos. Portanto, informar como se chega até à instituição é imprescindível. Já em 2009, todos os sites apresentam essas informações. O Histórico e o endereço das Instituições aumentaram de 95\% para 100\%, essas já eram informações que constavam na quase totalidade dos sites na primeira etapa, ainda assim, é muito positivo que na segunda aferição o índice tenha chegado a 100\%.

As informações sobre os sites exibiram crescimento em todos os aspectos, o que demonstra que os sites estão apresentando as instituições de maneira mais completa. As competências da instituição já tinham um bom índice em 2004, 85\%, agora aparecem em todos.

\subsection{Conteúdo - Aspectos Arquivísticos}

No que diz respeito aos aspectos arquivísticos propriamente ditos, a maioria das informações apresentadas é sobre o acervo das instituições. Em todos os itens, foram observados crescimentos: em relação às características gerais a diferença foi pequena, uma vez que, na primeira verificação, o índice já foi alto (95\%), mas, na segunda, atingiu 100\% dos sites, o que é muito positivo. Informações sobre a data limite do acervo cresceram de 90\% para 96,2\%; sobre as tipologias documentais, o aumento foi de $85 \%$ também para $96,2 \%$ e sobre a quantificação subiu de $70 \%$ para $84,6 \%$.

A importância da apresentação de informações sobre o acervo nos sites reside no fato de esta determinar a ida ou não do usuário ao arquivo. Se a instituição divulga seus fundos, que tipos de documentos contém, assuntos e datas-limite, permite que o usuário tenha uma informação preliminar sobre o acervo, o que faz com que ele possa decidir sobre as vantagens e desvantagens de sua ida ao arquivo. Sendo assim, o aumento dessas informações nos sites é muito válido.

Os Instrumentos de Pesquisa têm uma importância fundamental nos arquivos; têm a função de guiar o usuário através do acervo, de fazer a união entre o pesquisador e o documento. Esse deveria ser também um ponto alto no site. Os Instrumentos de Pesquisa vão permitir que o usuário chegue à informação desejada. Se o arquivo não atende às consultas pela internet, o simples fato de disponibilizar os Instrumentos de Pesquisa já permite que o usuário tome 
conhecimento do acervo e saiba se ali tem algo que interessa ou não - evitando uma ida desnecessária à Instituição, com deslocamentos, perda de tempo, etc.

Dada a importância dos instrumentos de pesquisa para a consulta às instituições arquivísticas, é muito significativo que tenha havido evolução nesse aspecto. A possibilidade de consulta aos instrumentos pelo site na internet aumentou de $60 \%$ para $80 \%$, o que é uma mudança muito positiva e a consulta a instrumentos através de bases de dados aumentou de $15 \%$ para 23\%.

Sobre a estrutura de atendimento ao usuário, em 2004, 14 (quatorze), 70\%, informam o horário de funcionamento e 16 (dezesseis), 80\%, informam as formas de atendimento. Em 2009, encontramos a estrutura de funcionamento do atendimento ao usuário em 24 sites - 92,3\%, o horário e as formas em 22 dos sites, ou 84,6\%. O atendimento ao usuário representa um aspecto importante que demonstra evolução entre as duas verificações.

Apesar de as consultas on-line representarem uma possibilidade de potencial ampliação dos serviços prestados, em 2004, apenas 4 (quatro) sites, 20\%, incluíam o atendimento a consultas pela Web entre eles. Em 2009, esse índice aumentou para 14 sites (53\%), essa talvez seja uma das mudanças mais importantes para que a ampliação dos serviços realmente venha a acontecer. O atendimento por correspondência estava presente, em 2004, em 5 (cinco) sites, 25\%, e, em 2009, aparece como opção em 9 (nove) sites, 34,6\%. A maioria menciona o atendimento no local, na sala de consulta, em ambas as análises: 18 (dezoito), 90\%, em 2004 e 25 (vinte e cinco) sites, 96,2\%, em 2009, às vezes incluindo o horário de funcionamento. A despeito disso, a maioria - 17 (dezessete) em 2004 e 22 (vinte e dois) em 2009 - divulga o e-mail da instituição no site, o que é uma forma de contato, de fazer alguma pergunta ou tirar alguma dúvida, ou até mesmo fazer uma consulta.

Em 2004, ficou claro que a maioria dos sites tinha como pressuposto a ida do usuário até a instituição para proceder a pesquisa. $\mathrm{O}$ fato de serem poucos os que atendiam pela web, reforçava a ideia de que o objetivo principal do site era mesmo servir como instrumento de divulgação. Em 2009, pode-se observar uma evolução desse quadro, já que houve aumento do índice de atendimento a consultas pela web, ainda que, mesmo crescendo de $20 \%$ para $53 \%$, o que é uma diferença considerável, ainda está próximo da metade dos sites, o que não é o suficiente para afirmar que o atendimento aos usuários dos arquivos públicos através dos sites na internet é representativo.

Enc. Bibli: R. Eletr. Bibliotecon. Ci. Inf., Florianópolis, n. esp., $1^{\circ}$ sem. 2011. ISSNe 1518-2924. 


\subsection{Desenho e Estrutura}

A importância desse aspecto reside no fato de o usuário encontrar o que procura com facilidade, simplicidade e agilidade. Além disso, o site deve transmitir as ideias com clareza e organização e permitir navegação e interfaces agradáveis. Dificuldades, lentidão e problemas técnicos prejudicam a relação do usuário com o site.

Em 2004, nenhum site utilizava imagem em movimento. Apesar de serem recursos passíveis de serem usados na internet, isso não acontecia, os sites apenas reproduziam documentos textuais ou impressos, um exemplo de apropriação da nova tecnologia com a mesma utilização da anterior.

Em 2009, o uso de imagem em movimento já é assinalado. O Arquivo Público Mineiro é o único que disponibiliza imagens em movimento para consulta na internet. São trechos de filmes do acervo que podem ser vistos no site. Além das imagens em movimento, é possível consultar os acervos fotográficos de revistas e de jornais. $\mathrm{O}$ arquivo disponibiliza também um vídeo institucional, onde é exposto o que é o arquivo, qual o trabalho realizado, entre outras informações sobre o acervo e a instituição, através de imagens em movimento e uma narração. $\mathrm{O}$ arquivo de Santos também tem um vídeo institucional, onde se pode conhecer o trabalho do arquivo, esse vídeo, além de estar disponível no site, também está no Youtube ${ }^{4}$.

A existência do vídeo institucional é um expediente criativo e atraente para apresentar o trabalho do arquivo de uma forma mais dinâmica do que os tradicionais textos e fotos, além de se apropriar dos recursos que a internet permite.

A possibilidade de consultar parte do acervo de imagem em movimento é uma evolução a ser registrada. Apesar de ainda incipiente, existe em apenas um site, mas já é um início e traduz-se em uma boa perspectiva para o futuro.

Em 2004, era possível fazer download para obter documentos institucionais em 8 (oito) sites, $40 \%$, e, em 2009, é possível em 12 sites, 46,2\%. Houve crescimento, porém pequeno. O recurso de disponibilizar documentos para download poderia ser mais utilizado na divulgação do acervo, dos instrumentos de pesquisa, de documentos, publicações, textos científicos e muitos outros.

\footnotetext{
${ }^{4}$ YouTube é um site que permite que seus usuários carreguem e compartilhem vídeos em formato digital. Hospeda uma grande variedade de filmes, videoclipes e materiais caseiros. O material encontrado no YouTube pode ser disponibilizado em blogs e sites pessoais através de mecanismos desenvolvidos pelo site.

Enc. Bibli: R. Eletr. Bibliotecon. Ci. Inf., Florianópolis, n. esp., $1^{\circ}$ sem. 2011. ISSNe 1518-2924. 
Alguns exemplos de documentos disponíveis para download: textos de evento; textos sobre Avaliação, Tabela de Temporalidade, Teoria das três idades, entre outros; Instrumentos de pesquisa; história da cidade; planilhas, questionários; download de publicações arquivísticas: de obras esgotadas, algumas "em breve"; Os de maior incidência na oferta ao usuário são os Instrumentos de Pesquisa.

Em 2004, estava presente em 7 (sete) sites, 35\%, o uso das imagens. Em 2009, há a utilização de ilustrações que efetivamente valorizam e auxiliam os objetivos do website em 22 (vinte e dois), $84,6 \%$ dos sites. A maioria dos sites usa nas suas páginas e seções imagens do acervo e/ou da Instituição Arquivística, a saber, as da fachada, dos depósitos, da equipe trabalhando. Em alguns casos, existem as exposições virtuais, onde se pode ver fotografias do acervo ou reproduções de documentos com a opção de acesso às imagens ampliadas e com maior resolução. Não há utilização de registros sonoros em ambas as consultas.

\subsection{Páginas}

As instituições arquivísticas com páginas na Internet foram analisadas utilizando um procedimento diverso do empregado para os sites. Foi preenchido o mesmo formulário, porém, somente a parte referente ao conteúdo - aspectos gerais e aspectos arquivísticos.

Em 2004, foram encontradas 9 páginas e, em 2009, são 19. Cabe observar que o número de páginas encontradas na pesquisa de 2009 é muito maior do que o de 2004, traduzindo-se no crescimento mais expressivo, de $110 \%$. E as páginas têm, entre si, níveis muito diferentes de apresentação das Instituições Arquivísticas, em alguns casos, apenas faz menção, indica a existência. Dependendo do caso, as informações sobre a Instituição e seu acervo são detalhadas em maior ou menor nível.

\section{CONSIDERAÇÕES FINAIS}

Os diversos dados coletados fornecem um panorama da situação arquivística brasileira em sua interface com a internet, na tentativa de atingir um público mais amplo, atentando, porém, para as limitações que já estavam presentes nas instituições e ainda as novas, as do tempo das redes. 
A transferência da informação arquivística tem início no recebimento do documento, porém inclui todas as fases do tratamento, até a divulgação do seu conteúdo. Um aspecto importante nessa transmissão é o seu aproveitamento pelo usuário, ainda que se considere a parcela inerente de incerteza ligada ao uso efetivo da informação transferida.

A imagem da internet é muitas vezes relacionada à ideia de democracia, de abertura, igualdade, como se o acesso fosse possível a todos - homens e mulheres, velhos e jovens, pobres e ricos sem exceções.

Na prática, a rede não é tão democrática; tampouco o acesso é indiscriminado, uma vez que vários aspectos são limitadores, tais como equipamentos, linhas telefônicas, "analfabetismo digital", entre outros que colocam a internet fora do alcance de grande parte da população mundial. No entanto, é indiscutível seu enorme potencial para a difusão da informação, e a possibilidade da democratização do acesso à informação pode minimizar as distâncias e seus efeitos negativos.

O quadro analisado em 2004 demonstrava claramente que as instituições arquivísticas gerenciavam as tecnologias atuais com parâmetros semelhantes aos utilizados em tecnologias anteriores. Isso pode ser visto na própria evolução da web. No início, a maior parte das informações disponíveis na rede era semelhante aos documentos impressos, textuais. Com o tempo e a adaptação aos novos ambientes, os sites foram se tornando mais complexos. Porém, com poucas exceções, os sites de instituições arquivísticas brasileiras ainda não saíram daquele estágio inicial.

De um modo geral, os sites das instituições arquivísticas brasileiras ainda apresentam-se com a estrutura dos documentos anteriores, em papel. Os guias dos arquivos, os catálogos, inventários, os instrumentos de pesquisa de um modo geral e, em muitos casos, os próprios documentos, são digitalizados e disponibilizados em PDF (Portable Document Format). Devemos ressaltar que, na falta de melhor alternativa, o recurso do PDF é uma solução interessante e muito correta para disponibilizar instrumentos de recuperação da informação que, por várias razões, não podem ser oferecidos online. No entanto, essa alternativa revela que, em muitos casos, as instituições arquivísticas brasileiras ainda não estão se beneficiando das vantagens e dos recursos que a internet permite. 
Na análise de 2009, pôde-se observar certo progresso nesse quadro. Uma das evidências disso é um maior número de instrumentos de pesquisas em bases de dados, o que indica uma evolução na possibilidade de interação com o usuário. Outro aspecto detectado em 2009 é a consulta a acervos de imagens em movimento, que não apareceu na primeira etapa da pesquisa e que demonstra uma melhor apropriação das possibilidades tecnológicas da internet. As mudanças ainda são discretas, mas demonstram que houve evolução no período estudado.

A transformação que a Internet impõe à transferência da informação arquivística permite uma maior possibilidade de acesso pelos usuários, bem como uma maior visibilidade institucional e social da instituição arquivística. Assim, ela pode vir a reposicionar a instituição arquivística como espaço público de acesso e legitimação.

As instituições arquivísticas estão se deparando com um desafio, o da época das redes eletrônicas, que virá a se somar às suas atividades anteriores. Frente às novas tecnologias da informação que possibilitam as redes eletrônicas, é de fundamental importância repensar todas as ações teórico-práticas que condicionariam os arquivos. Faz-se imperativo questionar suas premissas de gestão e difusão de documentos mediante a disponibilização de seu acervo na Internet.

A disponibilização de acervos arquivísticos na internet apresenta muitas vantagens - facilitar o acesso, atingir um público maior, ampliar o atendimento aos pesquisadores, permitir pesquisas, aumentar a divulgação, dentre outras; cabe realmente utilizar-se delas.

\section{REFERÊNCIAS}

BARRETO, Aldo de Albuquerque. A estrutura do texto e a transferência da informação. Data Grama Zero, Rio de Janeiro, v. 6, n. 3, jun. 2005. Disponível em: <http://www.dgz.org.br>. Acesso em: 23 jun. 2005.

BELLOTTO, Heloísa Liberalli. Arquivística humanística: da tecnologia ao humanismo. In: JORNADA ARQUIVÍSTICA DA UNIRIO, 11. 1997, Rio de Janeiro.

CASTELLS, Manuel. A sociedade em rede. São Paulo: Paz e Terra, 1999.

CÔRTES, Maria Regina Persechini Armond. Arquivo público e informação: acesso à informação nos arquivos públicos estaduais do Brasil. 1996. Dissertação (Mestrado em Ciência da Informação)-Escola de Biblioteconomia, Universidade Federal de Minas Gerais, Belo Horizonte, 1996.

Enc. Bibli: R. Eletr. Bibliotecon. Ci. Inf., Florianópolis, n. esp., $1^{\circ}$ sem. 2011. ISSNe 1518-2924. 
CUNHA, Murilo Bastos. Internet em 15\% dos lares brasileiros. Mensagem da lista de discussão [Bib_virtual] recebida em 18 set 2004. Disponível em:

$<$ http://listas.ibict.br/pipermail/bib_virtual/2004-September/000408.html>. Acesso em: $21 \mathrm{dez}$ 2004.

DIRETRIZES gerais para a construção de websites de instituições arquivísticas. Rio de Janeiro: Conselho Nacional de Arquivos, 2000.

FONSECA, Maria Odila Kahl. Arquivologia e Ciência da Informação. Rio de Janeiro: FGV, 2005.

. Direito à informação: acesso aos arquivos públicos municipais. 1996. Dissertação (Mestrado em Ciência da Informação)-Escola de Comunicação/IBICT/Universidade Federal do Rio de Janeiro, Rio de Janeiro, 1996.

FUNDAÇÃO HISTÓRICA TAVERA. Relatório sobre a situação do patrimônio documental do Brasil. In: MESA REDONDA NACIONAL DE ARQUIVOS, 1999. Caderno de textos. Rio de Janeiro: Arquivo Nacional, 1999. 43p.

GUIMARÃES E SILVA, Júnia. Socialização da informação arquivística: a viabilidade de enfoque participativo na transferência da informação. 1996. Dissertação (Mestrado em Ciência da Informação)-IBICT/Universidade Federal do Rio de Janeiro, Rio de Janeiro, 1996.

JARDIM, José Maria. O acesso à informação arquivística no Brasil: problemas de acessibilidade e disseminação. In: MESA REDONDA NACIONAL DE ARQUIVOS, 1999. Caderno de textos. Rio de Janeiro: Arquivo Nacional, 1999. 21p.

. A dimensão virtual dos arquivos na perspectiva das políticas de informação. In: SEMINÁRIO DE CAPACITACIÓN Y GESTIÓN EN ARCHIVOS Y DOCUMENTACIÓN, 2000, Buenos Aires. 10 p.

Entre o local e o virtual: os arquivos municipais na Internet. In: SIMPÓSIO INTERNACIONAL DE ARQUIVOS MUNICIPAIS, 2002. Rio de Janeiro, 2002. 8p.

Transparência e opacidade do Estado no Brasil: usos e desusos da informação governamental. Niterói: Eduff, 1999.

JARDIM, José Maria; FONSECA, Maria Odila. Estudos de usuários em arquivos: em busca de um estado da arte. In: ISEMINÁRIO INTERNACIONAL DE ARQUIVOS DE TRADIÇÃO IBÉRICA, 1., 2000, Rio de Janeiro. Rio de Janeiro: Associacion Latino Americana de Archivos, Arquivo Nacional, Conselho Nacional de Arquivos, 2000.16p.

OHIRA, Maria de Lourdes Blatt; CASTRO, Marília Beatriz de; SILVEIRA, Celoi da. Critérios para a avaliação de conteúdo dos sites dos arquivos públicos estaduais do Brasil.

Florianópolis, 2003. p. 20. Disponível em: <http://www.ciberetica.org.br/trabalhos/anais/65-100p1-100.pdf>. Acesso em: 17 maio 2005.

OHIRA, Maria de Lourdes Blatt; MARTINEZ, Priscilla Amorim. Acessibilidade aos documentos nos arquivos públicos municipais do Estado de Santa Catarina - Brasil. In: CONGRESSO INTERNACIONAL DE ARQUIVOS, BIBLIOTECAS, CENTROS DE DOCUMENTAÇÃO E MUSEUS, 1., 2002, São Paulo. Textos do Integrar. São Paulo: Imprensa Oficial do Estado, 2002. p. 335-358. 
OLIVEIRA, Daíse Apparecida. Os arquivos públicos e privados: estratégias para a institucionalização de arquivos municipais. In: MESA REDONDA NACIONAL DE ARQUIVOS, 1999. Caderno de textos. Rio de Janeiro: Arquivo Nacional, 1999. 22p.

SANTOS, Vanderlei Batista dos. Gestão de documentos eletrônicos: uma visão arquivística. 2. ed. Brasília: ABARQ, 2005.

SILVA, Armando B. Malheiro da; RIBEIRO, Fernanda; RAMOS, Júlio; REAL, Manuel Luís. Arquivística: teoria e prática de uma ciência da informação. Porto: Edições Afrontamento, 1998.

SILVA, Jaime Antunes. Por uma política nacional de arquivos. In: MESA REDONDA NACIONAL DE ARQUIVOS, 1999. Caderno de textos. Rio de Janeiro: Arquivo Nacional, 1999. 13p.

SORJ, Bernardo. Brasil@povo.com: a luta contra a desigualdade na sociedade da informação. Rio de Janeiro: Jorge Zahar Ed.; Brasília, DF: Unesco, 2003.

UNIVERSIDADE ESTADUAL PAULISTA “JULIO DE MESQUITA FILHO”. Norma técnica para exploração de publicidade nas homepages da UNESP. São Paulo: Unesp, 2000.

Disponível em: <http://www.unesp.br/ai/pdf/nt-ai.02.02.01.pdf>. Acesso em: 7 maio 2005.

\begin{abstract}
A study of the development of the introduction of the Brazilian Public Archival Institutions on the internet and of the processes of transferring archival information via the network. The first stage of the research, in 2004, started with the existing universe of sites of Brazilian Public Archival Institutions. In the second stage of the research in 2009, the universe was updated to analysis and the sites were investigated using the same criteria as the previous stage: the services that are available, the level of relationship with the user, the types of consultations that can be made to the collections and elements related to the content, the design and structure of the sites. The importance of this comparative study is to verify the changes that occurred during the interval, if there was growth and or advancements and if so, what they were. The site of an archival institution offers services already available at their physical locations, either totally or partially, as well as suggesting new possibilities to the archival institutions. This new electronic channel requires actions in order to attend the demands of the network users. The introduction of archival collections on the internet implicates new challenges in the management of this information.
\end{abstract}

Keywords: 1. Public Archives- Brazil. 2. Internet (Computer Networks). 3. Web sites- research. 4. Information Recovery Systems- Archives.

Originais recebidos em: 03/10/2010

Aceito para publicação em: 15/12/2010

Enc. Bibli: R. Eletr. Bibliotecon. Ci. Inf., Florianópolis, n. esp., 1º sem. 2011. ISSNe 1518-2924. 